Universidad Nacional de La Plata.

Facultad de Humanidades y Ciencias de la Educación.

Departamento de Educación Física

\title{
Disputas pela (des)estabilização do regime cisheteronormativo na Educação Física escolar
}

Destabilizing the cisheteronormativity regime in school Physical Education

Ana Paula da Silva Santos

apss.sol@gmail.com

Secretaria Municipal de Educação de Duque de Caxias, Brasil

Leandro Teofilo de Brito

teofilo.leandro@gmail.com

Escola de Educação Física e Desportos da Universidade Federal do Rio de Janeiro, departamento de Ginástica, Brasil D https://orcid.org/0000-0002-9123-5280

Resumo: Como recorte de uma pesquisa-ação que tensionou questões de gênero nas aulas de Educação Física, buscamos, neste artigo, problematizar como meninos e meninas enunciam sentidos de reprodução e desestabilização do regime cisheteronormativo presentes nas práticas pedagógicas da Educação Física escolar. Para isso, propomos a interlocução dos estudos de gênero e feministas pós-estruturalistas com a perspectiva intercultural crítica por autoras/es como como Judith Butler, Paul B. Preciado, Vera Candau e Marcos Neira, e operacionalizamos dois grupos de discussão, conforme a proposta de Wivian Weller, no início e ao final da pesquisa, com meninos e meninas estudantes do ensino fundamental. Entre os resultados, os discursos dos sujeitos enunciaram afetações diversas da cisheteronormatividade nas práticas da Educação Física escolar, seja pelas posições fixas para masculino e feminino nas aulas, como também das disputas pela desestabilização destes sentidos com o desenvolvimento da pesquisa.

Cita sugerida: Silva Santos, A. P. da y Brito, L. T. de. (2020). Disputas pela (des)estabilização do regime cisheteronormativo na Educação Física escolar. Educación Física y Ciencia, 22(4), e149. https:// doi.org/10.24215/23142561e149
Palavras-chave: Cisheteronormatividade, Gênero, Interculturalidade, Educação Física, Escola.

\begin{abstract}
As an excerpt from an action research that tensioned gender issues in Physical Education classes, we seek, in this article, to problematize how boys and girls enunciate meanings of reproduction and destabilization of the cisheteronormative regime present in the pedagogical practices of Physical Education at school. For this, we propose the interlocution of post-structuralist gender and feminist studies with a critical intercultural perspective by authors such as Judith Butler, Juliana Jardim, Vera Candau and Marcos Neira, and operationalized two discussion groups, according to Wivian's Weller proposal, at the beginning and at the end of the research, with boys and girls who are students of elementary school. Among the results, the subjects' speeches stated different affects of cisheteronormativity in school Physical Education practices, either by the fixed positions for male and female in classes, mainly at the beginning of the research, as well as the destabilization of these senses, by new looks, new ideas and new thoughts in relation to gender norms in classes, which have been reframed with the development of research.
\end{abstract}

Keywords: Cisheteronormativity, Gender, Interculturality, Physical Education, School.

\section{Introdução}

O contexto educacional brasileiro viveu nos últimos anos ataques de grupos políticos conservadores e religiosos a abordagens pedagógicas que se voltavam às questões de gênero e sexualidade nos currículos escolares. 
A enunciação "ideologia de gênero" produziu efeitos discursivos no campo da Educação, que materializaram-se com a retirada de termos como gênero, orientação sexual e sexualidade de documentos da política educacional, tais como o Plano Nacional de Educação (PNE), os planos municipais e estaduais, em várias partes do país e, mais recentemente, da Base Nacional Comum Curricular (BNCC). Com o intuito de controle sobre os currículos escolares para que os temas sejam não apenas invisibilizados, mas também banidos das escolas, o conservadorismo defendido por políticos reacionários enquadrou professores e professoras numa realidade de criminalização, caso abordassem os temas gênero e sexualidade em suas aulas.

A enunciação "ideologia de gênero" é um discurso reiterado pelo conservadorismo reacionário, que, em defesa de uma suposta "família tradicional”, se opõe a aspectos relacionados à saúde reprodutiva de mulheres, à educação sexual nas escolas e ao reconhecimento de identidades não heterossexuais entre os sujeitos (Miskolci, 2018). No campo da Educação ganhou contornos específicos, como pauta de defesa do Projeto Escola sem Partido, que aponta a escola como uma instância de ideologização partidária de esquerda e, entre suas posições mais radicais, a reiteração de um pânico moral de que professores e professoras ao abordarem temas como gênero e sexualidade em suas aulas estariam buscando homo/transexualizar crianças e jovens (Sousa Filho, 2015).

Contudo, neste mesmo cenário, resistências também se fazem presentes, como o ocorrido no mês de abril de 2020, quando o Superior Tribunal Federal (STF) reconheceu a inconstitucionalidade de proibição da abordagem das questóes de gênero nas escolas do município de Novo Gama - GO ${ }^{1}$. Sem desconsiderar o fato como uma vitória das lutas travadas por movimentos feministas e LGBTI+ neste contexto de disputa, é provável que o fantasma da "ideologia de gênero" ainda se faça presente pelas ações cotidianas de empreendedores de um pânico moral posto socialmente (Duque, 2020) e que continua firme e forte no propósito de desqualificar o trabalho docente que se engaja nas lutas políticas pelas diferenças. Nesta discussão, reconhecemos a noção de diferença como sinônimo de igualdade, um debate bastante consolidado nos estudos feministas contemporâneos, que postula que a igualdade não é a eliminação da diferença e a diferença não exclui a igualdade, pois considera-se que a noção política de igualdade abarca a existência da categoria diferença (Scott, 1994).

Para subsidiarmos o presente estudo recorremos à perspectiva intercultural crítica (Candau, 2018), buscando problematizar as diferenças de gênero por meio da inter-relação e diálogo entre masculino e feminino. Nesse sentido, reconhecemos que tal perspectiva rompe com a visão essencialista da construção das culturas e identidades culturais e afirma que a sociedade atual é marcada por intensos processos de hibridização que definem as identidades como abertas e em permanente construção. A perspectiva intercultural crítica, segundo Candau (2018), desnuda os mecanismos de poder que permeiam as relaçóes culturais, entendendo que tais relações não são puras e românticas, mas são 
construídas em um processo histórico e, portanto, atravessadas por questões de poder fortemente hierarquizadas e marcadas por preconceitos e discriminações entre os diferentes grupos.

No âmbito escolar, podemos pensar a interculturalidade crítica por intermédio da educação intercultural (Pineda, 2009), representada por práticas pedagógicas culturalmente situadas, que valorizem as diferenças e promovam a igualdade, levando em consideração diferentes vozes e visões de mundo. Para Pineda (2009), o diálogo intercultural não é uma atitude inerente aos sujeitos, mas pode ser construído na intenção de promover relações democráticas e justas entre diferentes grupos.

Deste modo, buscamos o diálogo entre a perspectiva intercultural e os estudos de gênero e feministas pós-estruturalistas, que reconhecem que cultura, poder e linguagem trabalham na constituição dos sentidos sociais do masculino e do feminino (Scott, 1994). Para a teórica e filósofa feminista Judith Butler, o gênero é uma contínua repetição estilizada do corpo que, por meio das normas da heterossexualidade reprodutora, busca enquadrar os sujeitos de maneira inteligível e coerente com a premissa sexo-gênero-desejo (Butler, 2015). Um processo contingente e que Butler (2018, p. 39-40) nomeia de performatividade de gênero:

[...] dizer que o gênero é performativo é dizer que ele é um certo tipo de representação; o "aparecimento" do gênero é frequentemente confundido com um sinal de sua verdade interna ou inerente; o gênero é induzido por normas obrigatórias que exigem que nos tornemos um gênero ou outro (geralmente dentro de um enquadramento estritamente binário); a reprodução do gênero é, portanto, sempre uma negociação com o poder; e, por fim, não existe gênero sem essa reprodução das normas que no curso de suas repetidas representações corre o risco de desfazer ou refazer as normas de maneiras inesperadas, abrindo a possibilidade de reconstruir a realidade de gênero de acordo com novas orientações.

Conforme destaca Salih (2012), Judith Butler busca com a noção de performatividade de gênero descrever os processos pelos quais o indivíduo vem assumir sua posição como sujeito no social e que, neste processo, as identificações de gênero são constituídas no interior da linguagem e do discurso. Deste modo, Judith Butler "supõe que sexo e gênero são efeitos - e não causas - de instituições, discursos e práticas; em outras palavras, nós, como sujeitos, não criamos ou causamos as instituições, os discursos e as práticas, mas eles nos criam e causam, ao determinar nosso sexo, nossa sexualidade e nosso gênero" (Salih, 2012, p. 21).

Neste sentido, os corpos para Butler (2019) nunca estão suficientemente completos, do ponto de vista de sua materialização. Assim, a performatividade deve ser entendida como uma prática repetida e citacional em que o discurso produz os efeitos daquilo que pretende nomear e que as normas regulatórias "trabalham de forma performativa para constituir a materialidade dos corpos e, mais especificamente, para materializar o sexo do corpo, para materializar a diferença sexual a serviço da consolidação do imperativo heterossexual” (Butler, 2019, p. 16).

Essa materialização do corpo pode ser facilmente associada ao campo da Educação Física. Conforme destacam Devide, Osborne, Silva, Ferreira, Saint Clair \& Nery (2011) e Goellner (2014), os estudos de gênero na área 
da Educação Física brasileira surgiram no início dos anos de 1980, com a inserção de professoras e professores como estudantes em programas de Pós-graduação em Ciências Humanas e Educação e, posteriormente, em programas da área de Educação Física, que tiveram seu início mais tardio e contemplavam, inicialmente, enfoques voltados para as áreas biológicas. A entrada do conceito de gênero na Educação Física buscou, justamente, contrapor o discurso do determinismo biológico que era imposto à materialização de corpos de homens e mulheres:

Os estudos de gênero e feministas, ao apontarem que os corpos não se traduzem em matéria universalmente edificada pelos desígnios da natureza, enfatizaram a importância da utilização do "gênero" como uma categoria analítica, visto que esse conceito é importante para perceber os processos pelos quais, no interior das redes de poder, a diferença biológica é tomada para explicar desigualdades sociais, gestando, assim, formas de inclusão e exclusão de sujeitos e grupos (Goellner, 2014, p. 25).

Assim, entre as focalizações iniciais dos estudos de gênero na Educação Física ganhou destaque a problemática de uma suposta fragilidade das mulheres nas práticas corporais e esportivas (Goellner, 2014). Em revisão da literatura brasileira, Devide et al. (2011) apontam que estes estudos se desdobraram em outras temáticas, tais como a história das mulheres nos esportes, mulheres em posições de comando em equipes esportivas, mulheres na mídia esportiva e a participação de meninos e meninas em aulas conjuntas na Educação Física escolar, temática ${ }^{2}$ que vamos nos debruçar neste artigo.

A questão das aulas separadas por sexo ${ }^{3}$, mistas ou coeducativas foi bastante abordada nas pesquisas que se detiveram nas relações entre meninos e meninas na Educação Física escolar. Estas pesquisas discutiram os conflitos vivenciados por alunos e alunas nas aulas, evidenciando os processos de subalternização das meninas nas aulas mistas, a generificação dos conteúdos, o desenvolvimento de aulas coeducativas e até mesmo os mecanismos de exclusão por habilidade motora em aulas separadas por sexo (Sousa \& Altmann, 1999; Devide, Lima, Batista \& Rodrigues, 2010; Dornelles, 2011; Corsino \& Auad, 2012; Brito \& Santos, 2013; Santos $\&$ Canen, 2014, entre outros/as).

Ampliamos esse olhar neste artigo, discutindo a Educação Física escolar e o atravessamento da cisheteronormatividade. Reconhecemos que não inauguramos essa discussão na área, pois pesquisadores e pesquisadoras já desenvolveram a abordagem em textos que trouxeram a teorização da heteronormatividade como operador político-analítico nas práticas da Educação Física escolar (Dornelles \& Dal'igna, 2015; Garcia \& Brito, 2018).

A noção teórica de heteronormatividade, cunhada por Warner (1991), refere-se a normatizações da ordem social que, por um conjunto de dispositivos como discursos, valores e práticas, parte do pressuposto de que a heterossexualidade é a única possibilidade de orientação sexual a ser vivenciada pelos sujeitos. Neste sentido, estes sujeitos são submetidos ao controle e à regulação, não apenas no que concerne à orientação sexual propriamente dita, mas também na imposição de 
padrões de comportamentos atrelados ao binarismo de gênero. Conforme complementa Junqueira (2012, p. 282-283): "seus dispositivos atuam capilarmente em processos heteronormalizadores de vigilância, controle, classificação, correção, ajustamento e marginalização com os quais todos/ as somos permanentemente levados/as a nos confrontar".

Concordamos com Dornelles \& Wenetz (2019, p. 41), que posicionam a Educação Física escolar como uma "tecnologia social heteronormativa", tomando como base preceitos do filósofo queer Paul B. Preciado para pensar que a disciplina no âmbito escolar aciona o sexo como uma tecnologia biopolítica dos corpos, definindo-os numa bipolaridade normativa feminino e masculino. Para as autoras, uma proposta pedagógica da Educação Física escolar, que se fundamenta em acionar o sexo como referência para constituir expressões de gênero binárias e naturalizadas "investe e insiste na produção do sujeito aluno posicionado de modo central no plano das heteronormas" (Dornelles \& Wenetz, 2019, p. 47). Como coloca Preciado (2014), a tecnologia social heteronormativa reproduz nos corpos, nos espaços e nos discursos uma suposta articulação entre natureza humana e heterossexualidade, um dispositivo social de produção de masculinidades e feminilidades normalizadoras. $\mathrm{O}$ autor ainda complementa que:

A tecnologia social heteronormativa (esse conjunto de instituiçóes tanto linguísticas como médicas ou domésticas que produzem constantemente corposhomem e corpos-mulher) pode ser caracterizada como uma máquina de produção ontológica que funciona mediante a invocação performativa do sujeito como corpo sexuado (Preciado, 2014, p. 28).

Neste contexto, propomos a ampliação da noção de heteronormatividade, com uso do prefixo cis, referente à identificação cisgênero: significação que diz respeito a pessoas que se identificam com o gênero de nascença. Entre os sujeitos desviantes do regime cisheterornormativo, incluem-se, conforme Couto Junior, Brito, Pocahy \& Amaro (2019), aqueles e aquelas que não se identificam como heterossexuais e que performatizam masculinidades e feminilidades em desconformidade com a identificação de gênero atribuída no momento do nascimento. Jardim (2020) postula que a cisheteronormatividade corresponde às normas político-sociais que impõem práticas e códigos cisgêneros e heterossexuais a todas as pessoas.

Como recorte de uma pesquisa mais ampla ${ }^{4}$, que discutiu o desenvolvimento de aulas de Educação Física escolar fundamentadas na perspectiva intercultural para tensionar as aulas mistas, buscamos, neste artigo, problematizar como meninos e meninas enunciam sentidos de reprodução e desestabilização do regime cisheteronormativo presentes nas práticas pedagógicas da Educação Física escolar. Na sequência, apresentaremos os caminhos metodológicos de desenvolvimento de nossa pesquisa. 


\section{Metodologia}

Nossas escolhas metodológicas para a realização da pesquisa fundamentam-se nas proposições de Meyer \& Paraíso (2014). As autoras propóem caminhos alternativos para abordar questões da diferença na pesquisa acadêmica, sobretudo no campo da Educação, por meio de estratégias que dizem respeito a formas mais ou menos rígidas de condução do processo investigativo, sem perder o rigor científico, e reconhecendo que uma metodologia pode ser construída no desenvolvimento da pesquisa, seja pelo objeto focalizado, seja pelas perguntas formuladas, teorizações propostas, entre outros/as. Tais abordagens teóricas são nomeadas como pós-críticas:

Essas pesquisas usam ou se inspiram em uma ou mais abordagens teóricas que conhecemos sob o rótulo de 'pós' - pós-estruturalismo, pós-modernismo, póscolonialismo, pós-gênero, pós-feminismo - e em outras abordagens que, mesmo não usando em seus nomes o prefixo 'pós", fizeram deslocamentos importantes em relação às teorias críticas - Multiculturalismo, Pensamento da Diferença, Estudos Culturais, Estudos de Gênero, Estudos Étnicos e Raciais e Estudos Queer, entre outros (Meyer \& Paraíso, 2014, p. 19).

Neste processo, uma metodologia pós-crítica se mostra atenta para operar com questões de gênero, sexualidade, raça/etnia, geração, classe, entre outras categorias das diferenças, buscando inspiração em diferentes textos, autorias, linguagens e artefatos para fazer perguntas e interrogar o material produzido no campo de pesquisa de diferentes modos, assim como multiplicar sentidos e mostrar as contingências e acontecimentos que emergem nos contextos de pesquisa (Meyer \& Paraíso, 2014).

Buscando problematizar enunciações de meninos e meninas, estudantes do ensino fundamental, sobre o regime da cisheteronormatividade na Educação Física escolar, operacionalizamos a produção dos relatos dos sujeitos por meio de entrevistas coletivas como recorte de uma pesquisa mais ampla, que foi configurada por princípios de uma pesquisa-ação ${ }^{5}$. No desenvolvimento desta pesquisaação, operacionalizamos duas entrevistas coletivas, que nomeamos como grupos de discussão (Weller, 2006), realizadas no início e ao final do processo. Os grupos de discussão, como método de pesquisa, passaram a ser utilizados a partir da década de 1980, sobretudo nas pesquisas sobre as categorias infância e juventude, como aponta Weller (2006). Sua operacionalização é potente para investigar experiências coletivas, assim como características sociais específicas de um grupo, tais como questões relacionadas a gênero, sexualidade, geração, raça e classe, por exemplo, constituindo uma ferramenta importante para discutir vivências que orientam as ações cotidianas dos sujeitos, além de que

[...] os grupos de discussão representam um instrumento por meio do qual o pesquisador estabelece uma via de acesso que permite a reconstrução dos diferentes meios sociais e do habitus coletivo do grupo. Seu objetivo principal é a análise dos epifenômenos (subproduto ocasional de outro) relacionados ao meio social, ao contexto geracional, às experiências de exclusão social, entre outros. A análise do discurso dos sujeitos, tanto do ponto de vista organizacional como 
dramatúrgico, é fundamental e auxiliará na identificação da importância coletiva de um determinado tema (Weller, 2006, p. 247).

Os grupos de discussão foram realizados no ano letivo de 2011, período em que se desenvolveu a pesquisa mais ampla, numa escola municipal do bairro de Campo Grande, zona oeste da cidade do Rio de Janeiro. No contexto da pesquisa, os grupos de discussão foram formados com 20 meninas e 17 meninos do $5^{\circ}$ ano de ensino fundamental, totalizando 37 estudantes com idades entre 10 e 11 anos. Entendemos que a pesquisa com a infância, em acordo com Felipe (2009), deve levar em consideração e visibilizar a criança nas mais variadas experiências: como sentem, o que pensam e como agem, mas desvinculadas de uma visão adultocêntrica, ainda que existam limites no olhar para a criança como protagonista deste processo. $\mathrm{O}$ pesquisador e a pesquisadora também devem ter atenção ao que as crianças falam numa entrevista, mas também àquilo que pessoas adultas presentes nos espaços educativos - professoras, professores, direção, e responsáveis - falam sobre e para elas. Os discursos infantis, para Felipe (2009), trazem consigo diversas vozes, que estão imbricadas na cultura e nas relações de poder. A autora ainda afirma:

No entanto, torna-se importante salientar que o fato de ouvir as crianças, colocando-as como sujeitos privilegiados de nossas pesquisas, não fará com que nos aproximemos de uma verdade natural e absoluta sobre elas. É ilusão pensar que "dar" voz às crianças, observando atentamente os discursos que elas produzem ou reproduzem sobre si mesmas e o mundo nos trará um desvelar sobre a infância (Felipe, 2009, p. 8).

Tomando como referência tais princípios, em interlocução com a proposta de Weller (2006), operacionalizamos os grupos de discussão no contexto da pesquisa, da seguinte maneira: dirigimos uma pergunta inicial como tema geral da pesquisa ao grupo como um todo e estimulamos que os/as participantes interagissem entre si; nesta discussão inicial, permitimos, dentro de certos limites, que meninos e meninas se organizassem na ordenação das falas e dialogassem entre si; formulamos perguntas que gerassem narrativas e não mera descrição dos fatos, priorizando o "como" em detrimento do "por que", conforme o exemplo: "Como meninas e meninos se organizam para jogar futebol nas aulas de Educação Física?”. Num segundo momento, ao percebermos que a primeira pergunta geral se esgotou em discussão pelo grupo, fizemos nova pergunta, com o objetivo de aprofundar ou esclarecer os aspectos discutidos até então. $\mathrm{Na}$ sequência, discutiremos parte dos resultados destes dados construídos com os grupos de discussão.

\section{Resultados e discussão}

O primeiro grupo de discussão ocorreu no início do ano letivo de 2011, com meninos e meninas sentados/as e dispostos/as em círculo no pátio da escola. As respostas foram anotadas em um diário de campo, bem como as reações da turma no momento dos questionamentos. É importante salientar que os relatos são decorrentes do contexto cultural 
mais amplo do qual pertenciam, conforme já discutimos anteriormente, pelas afetações mútuas que decorrem deste processo. Ao perguntarmos se já haviam sofrido preconceito por serem menina ou menino e de que forma isso acontecia no âmbito dos jogos e das brincadeiras, percebemos uma nítida distinção de gênero em relação às vivências práticas nas aulas de Educação Física:

Já deixei de jogar futebol por ser menina porque os meninos ficaram me zoando (Aluna P).

Já fiquei com medo de jogar queimado com todo mundo junto, porque os meninos falaram que iam me estourar porque eu era menina e não ia aguentar (Aluna F).

A gente quer jogar futebol e os meninos não deixam, mas quando eles querem jogar queimado a gente deixa (Aluna $\mathrm{M}$ ).

$\mathrm{Na}$ Educação Física, as meninas não deixam os meninos jogar queimado com elas (Aluno K).

Interpretando estas falas, identificamos de imediato a problemática da generificação dos conteúdos, bastante debatida nas pesquisas sobre gênero na Educação Física escolar (Sousa \& Altmann, 1999; Dornelles, 2011, entre outros/as), que direciona meninos e meninas para vivências, comumente, distintas e específicas, tais como futebol é coisa de menino e queimado coisa de menina. Nos relatos, também nos chamou a atenção a dominância do masculino nos jogos e nos esportes vivenciados nas aulas (Moraes e Silva \& César, 2012; Brito \& Santos, 2013; Pereira \& Brito, 2018), significadas pela exclusão das meninas que se inibem de jogar futebol e até mesmo queimado em atividades mistas, quando a suposta "força física superior" dos meninos é enunciada. Ainda que num dos relatos, um menino - aluno $\mathrm{k}$ - afirme que as meninas não o deixaram jogar queimado, os sentidos da masculinidade como dominante no espaço da Educação Física mostraram maior força nas falas destacadas.

Conforme Dornelles \& Wenetz (2019), as práticas pedagógicas da Educação Física escolar, sobretudo o esporte, trabalham na produção de corpos sexuados, filiados ao gênero binário e expoente de uma sexualidade heterossexual. Deste modo, a produção dos corpos sexuados como mulheres, dentro deste plano discursivo normalizador, conforme pontuam as autoras, parece ser incompatível com a experimentação e reconhecimento dos elementos da cultura corporal, em especial nos jogos e esportes, já que experiências de corpos femininos se torna mais vigiada e controlada no que diz respeito à reiteração de uma feminilidade singular, performatizada, ao nosso ver, como cisheteronormalizadora. A dominação dos meninos, nos jogos e esportes vivenciados nas aulas de Educação Física escolar, denota um conjunto arbitrário de regulações inscritas nos corpos dos sujeitos, que, conforme afirma Preciado (2014, p. 26), asseguram a exploração de um sexo sobre o outro: "Os homens e as mulheres são construções metonímicas do sistema heterossexual de produção e de reprodução que autoriza a sujeição das mulheres como força de trabalho sexual e como meio de reprodução". Neste contexto, a fala do aluno $\mathrm{k}$, que afirma que as meninas não os deixam jogar queimado, pode ser significada como uma resposta de resistência ao domínio 
masculinista nas práticas da Educação Física escolar. Todavia, este domínio também é colocado em xeque quando uma suposta sexualidade dissidente articulada à masculinidade é acionada nas aulas:

Deixei de jogar queimado com as meninas porque os meninos ficavam me chamando de "boiolinha" e já deixei de dançar porque todo mundo falava que era "coisa de mulher" (Aluno J).

As meninas brincam de pique-bandeira, aí quando eu peço pra brincar, elas me chamam de "boiola" (Aluno L).

Teve uma vez que os meninos ficaram chamando a gente de "viadinho" só porque a gente estava brincando com as meninas (Aluno Y).

Destacamos nos excertos, a masculinidade heterossexual sendo posta em questionamento, quando meninos atravessam as fronteiras generificadas impostas historicamente sobre os elementos da cultura corporal. Além da dança, culturalmente tida como uma prática corporal feminina, jogos e brincadeiras, quando vivenciados majoritariamente por meninas, conforme os relatos, naturalizam-se como uma prática restritamente feminina e meninos que ousam adentrar nestes espaços serão tidos como dissidentes. Para Prado \& Ribeiro (2016), corpos de meninos que não se adequam ao modelo de masculinidade tomado como legítimo nas aulas de Educação Física são rechaçados e marcados negativamente para que possam ser enquadrados como "não apropriados" e essa marcação, recorrentemente, ocorre por meio de chacotas, piadas e brincadeiras que visam subjugá-los como um outro. Uma representação abjeta do sujeito como homossexual ou como aquele que não performatiza uma masculinidade próxima da considerada aceitável. Garcia \& Brito (2018), em pesquisa que focalizou meninos dissidentes das normas da masculinidade nas aulas de Educação Física escolar, apontaram que ao serem tidos como seres abjetos naquele espaço, estes meninos resistiam muitas vezes sozinhos ao regime cisheteronormativo por violências simbólicas e físicas ocorridas nas aulas e que ratificavam o estado de corpo abjeto: "Isso ocorre aos que fogem da heteronorma, sinalizando a existências de hierarquias que classificam e interpretam sujeitos heterodissidentes enquanto seres miseráveis em dignidade e/ou possuidores de vidas/corpos menos importantes" (Garcia \& Brito, 2018, p. 1329).

Judith Butler, ao enunciar o termo abjeção, refere-se "aquilo que foi expelido do corpo, descartado como um excremento, tornado literalmente 'o outro'” (Butler, 2015, p. 230), uma matriz que produz seres que não alcançam o estatuto de sujeitos, ainda que esse signo do "inabitável" e do "não vivível", impostos sobre os corpos abjetos, os circunscrevem num certo domínio de sujeito que também reivindica a vida social e o reconhecimento pela resistência. Assim, tais sujeitos abjetos, tidos como dissidentes nas aulas de Educação Física escolar, pela leitura dos relatos dos meninos, mostra que a performatização da masculinidade não normativa é produzida simultaneamente pela força da exclusão e, consequentemente da abjeção, pois:

A formação de um sujeito requer identificação com o fantasma normativo do "sexo" e essa identificação toma lugar mediante um repúdio que produz um 
domínio de abjeção, um repúdio sem o qual o sujeito não pode emergir. Esse é um repúdio que cria uma valência de abjeção e sua condição para o sujeito como um espectro ameaçador. Além disso, a materialidade de um determinado sexo vai se preocupar sobretudo com a regulação das práticas identificatórias de tal forma que a identificação com a abjeção de sexo será persistentemente repudiada (Butler, 2019, p. 19).

Como destacado anteriormente, tivemos como inspiração para a pesquisa mais ampla a metodologia da pesquisa-ação (Thiollent, 2011), pelo fato desta perspectiva metodológica buscar a compreensão crítica da realidade, onde a construção dos dados se dá por um processo coletivo dos sujeitos participantes da pesquisa intentando promover reflexões que busquem a superação de preconceitos e opressões, no nosso caso específico, as questões de gênero na Educação Física escolar. Neste sentido, meninos e meninas, no desenvolvimento da pesquisa, vivenciaram 10 aulas, distribuídas em atividades em sala de aula (apresentação de vídeos, leitura e produção de textos, debates, trabalhos em grupo e individual) e vivências de práticas corporais na quadra. Buscamos confrontar os processos de normalização em relação ao gênero, identificados nesta fase inicial da pesquisa, pela tematização da cultura corporal (o jogo, o esporte, a dança, as lutas e as brincadeiras populares) interpretadas pela perspectiva intercultural e os estudos de gênero e feministas pós-estruturalistas.

Para a organização das aulas, utilizamos como suporte teórico as análises de Neira \& Nunes (2009) e Neira (2011), no que diz respeito a adoção de um currículo pós-crítico da Educação Física. Para estes autores, esta perspectiva é considerada como uma prática de significação, onde os/as docentes envolvidos procuram romper com uma visão cristalizada de reprodução de estereótipos e aprofundar a compreensão da prática pedagógica como uma atividade de análise social e cultural, de crítica, de oposição, de desnaturalização. A aula de Educação Física pode se tornar um espaço de problematização das diferenças e, no caso do presente texto, um espaço de enunciação de discursos, linguagens, comportamentos e atitudes que desestabilizam sentidos da cisheteronormatividade presentes nas relações entre os sujeitos. Neira (2011, p.49) ressalta que:

O currículo cultural da Educação Física cumpre a função de expor as hipóteses ingênuas que normalmente permeiam as ressignificações sofridas por uma prática cultural qualquer. Se o que se pretende é formar cidadãos/ãs para uma sociedade menos desigual, como não debater as questões de gênero presentes na trajetória do futebol e do voleibol? Ou as questóes de classe e etnia presentes na trajetória do hip-hop e do rap? Como não indagar as questões de classe, gênero, cultura e etnia incrustadas no percurso histórico das ginásticas?

A aula de Educação Física reconhecida como espaço de igualdade e democracia precisa, além de valorizar e reconhecer as diferenças, possibilitar que os/as estudantes compreendam os processos de subordinação e dominação presentes nas relações entre os diferentes grupos culturais e, com isso, sejam capazes de produzir novas visões de mundo, sentidos e significados atribuídos às diferenças. Neste contexto, Neira \& Nunes (2009) afirmam que os/as educadores/as inspirados/as pelos conhecimentos silenciados/apagados pela escola, por não fazerem 
parte do conhecimento universalmente aceito, reescrevem durante suas aulas uma nova prática pedagógica de cunho democrático. Os autores citados propóem que não se trata de incorporar o conhecimento subordinado de forma folclórica e descontextualizada, mas questionar sentidos e significados de forma crítica desvelando preconceitos e discriminações presentes na sociedade.

Deste modo, todas as observações realizadas durante as aulas propostas foram registradas em um diário de campo e analisadas à luz das perspectivas pós-críticas já anunciadas. Ao final, utilizamos mais uma vez a proposta do grupo de discussões, para levantarmos as possíveis e importantes contribuiçóes da pesquisa para os sujeitos participantes e para a realidade da escola. Perguntamos ao grupo se houve mudança no comportamento da turma após a participação na pesquisa e obtivemos um bom retorno nos diálogos travados no grupo de discussão. Entretanto, antes de problematizarmos estes discursos, destacamos duas falas que nos chamou atenção:

Os meninos começaram a deixar a gente jogar sem ficar ofendendo a gente (Aluna $\mathrm{X})$.

Até que foi legal jogar com as meninas, mas no futebol a gente ainda é melhor! (Aluno Y).

Os discursos apontam os avanços propostos pela pesquisa, mas também enunciam novamente as afetações diversas da cisheteronormatividade nas práticas da Educação Física escolar. A aluna x destaca que as meninas passaram a não ser mais ofendidas pelos meninos nas aulas conjuntas e o aluno y além de apontar a positividade das vivências práticas com as meninas, retoma o discurso de poder dos meninos, especificamente à suposta dominância dos mesmos em relação à habilidade motora no futebol. Recentemente, a sociedade contemporânea vem colocando em discussão a chamada masculinidade tóxica, uma forma muito tradicional de educar meninos e jovens nos modelos normalizadores, tais como a aproximação com aspectos da violência e a recusa de emoções, e que hoje sabe-se que gera desordem psíquica tanto para mulheres como para os próprios homens (Castro, 2018). A masculinidade tóxíca pode ser facilmente associada ao regime da cisheteronormatividade, contribuindo para que identidades que fujam dos sentidos fixados pelo binarismo de gênero sejam subalternizadas nos diferentes contextos sociais, sobretudo na escola. Conforme aponta Jardim (2020), a cisheteronormatividade impõe o modelo cisgênero para todas as pessoas, sejam elas trans ou cisgêneras, enquadrando-as em códigos e comportamentos que comumente são direcionados às normatizações do masculino e feminino. Por exemplo, uma menina que seja habilidosa nos esportes e que se apresente nos jogos com o mesmo nível de habilidade que um menino, certamente estará contestando o regime cisheteronormativo e, conforme o contexto, poderá sofrer sanções por isso. Assim, ainda que nas práticas pedagógicas da Educação Física escolar, meninas sejam estimuladas à prática do futebol, conforme ocorreu na pesquisa, esta prática ainda é afetada por discursos essencialistas que carregam rastros históricos de subordinação e exclusão da participação das mulheres nos esportes. Em 
contraponto a estas enunciações, seguem as outras falas deste grupo de discussão final:

Eu acho que os meninos podem jogar junto com as meninas sim. Só tem que respeitar (Aluno L).

A gente aprendeu que todo mundo pode ter o mesmo direito de jogar futebol (Aluna L).

Eu penso que tudo isso não tem nada a ver. Meninas podem jogar futebol e meninos podem brincar de cozinha (Aluna $\mathrm{M}$ ).

Pra mim todos os jogos são de todos (meninos e meninas) e ninguém deve ser excluído de nada. Todos nós somos iguais (Aluna $\mathrm{M}$ ).

Todos os jogos são unisssex, tanto menina quanto menino podem jogar, juntos ou sozinhos (Aluna T).

Os meninos e as meninas têm que ter o direito de fazer coisas iguais (Aluna B).

Eu acho que quando junta menino com menina fica muito mais divertido (Aluna L).

Constatamos assim, que, de uma maneira geral, houve um tensionamento nos discursos de meninos e meninas em relação às aulas conjuntas e às vivências nas atividades propostas, mostrando, em alguma medida, maiores reflexões sobre o tema. As trocas dialógicas entre meninos e meninas neste grupo de discussão final nos mostrou olhares mais ressignificados em relação às normatizações de gênero presentes nas aulas de Educação Física, participando das disputas pela desestabilização do regime cisheteronormativo. Reconhecemos que é nas aulas de Educação Física que encontramos maior resistência ao trabalho integrado entre meninos e meninas, pois o viés biológico, ainda presente em rastros que se materializam no cotidiano das práticas, encontram-se sob uma ótica monocultural baseada na cultura branca, classista, cisgênera e heterossexual. As performatizações de gênero de meninos e meninas nas aulas de Educação Física podem e devem ser plurais e múltiplas, não se fixando em regulações que restringem sentidos do masculino e feminino. Assim, a intervenção de professores e professoras torna-se fundamental para a construção de práticas corporais plurais que valorizem as diferentes culturas e que contribuam para relações mais igualitárias e equitativas, conforme a pesquisa mais ampla buscou tensionar.

\section{Conclusões}

Conforme as discussões travadas neste texto, buscamos problematizar os processos de desestabilização do regime cisheteronormativo presente nas práticas pedagógicas da Educação Física escolar, por meio dos discursos de meninos e meninas que foram sujeitos de uma pesquisa mais ampla que focalizou as questões de gênero nas aulas da referida disciplina. Entre os resultados iniciais dos diálogos desenvolvidos no primeiro grupo de discussão, estivemos diante de enunciações que apontavam para a generificação dos conteúdos, para a dominância dos meninos frente às meninas nas atividades propostas, sobretudo nos jogos e esportes, porém, uma dominância com certa resistência, que, como resposta, também apresentava um questionamento da masculinidade 
heterossexual qualificando-a como abjeta. Ao final da pesquisa-ação, propusemos novo grupo de discussão e as respostas trouxeram um cenário que caminhou para um processo inicial de questionamento ao regime cisheteronormativo nas aulas.

Tensionar sentidos da cisheteronormatividade no contexto da Educação Física escolar permite que uma educação democrática, plural e aberta ao reconhecimento das diferenças participe das disputas que estabilizaram a disciplina Educação Física no contexto da escola como um espaço interpretado, em seu sentido restrito, pelos aspectos biológicos e que posicionou meninos e meninas em lugares imutáveis em relação às questões de gênero. Neste sentido, a perspectiva intercultural crítica, utilizada como suporte teórico neste estudo, contribuiu para pensarmos as diferenças de gênero como riquezas que ampliam nossas experiências e aumentam nossa sensibilidade em relação à construção de relações democráticas, igualitárias e justas. E para tanto, desconstruir e desnaturalizar aspectos que nos impedem de reconhecer positivamente estas diferenças se torna fundamental para a Educação Física escolar. Deste modo, a escola na contemporaneidade deve se afastar do seu caráter homogeneizador e monocultural, que historicamente silenciou sujeitos tidos como subalternizados e excluídos por relações de poder assimétricas. Pensar, tensionar, respeitar e reconhecer as diferenças nos processos pedagógicos é o grande desafio das instituições educacionais no século XXI.

Por fim, finalizamos este artigo no desejo de que esta pesquisa possa não só estimular professores e professoras de Educação Física escolar ao trabalho pedagógico com as questões de gênero e sexualidade em suas aulas, mas, principalmente, encorajá-los/as ao desafio da resistência, (re)existência e insurgência cotidiana aos ataques direcionados à educação democrática. Ainda que os temas gênero e sexualidade estejam silenciados em documentos oficiais de Educação no Brasil, o compromisso com as lutas políticas favoráveis às diferenças nos coloca ao desafio da (re)invenção constante, seja em nossas pesquisas, seja em nosso cotidiano como docentes engajados/as nas mudanças sociais.

\section{Referências bibliográficas}

Barroso, L. B., Silva, W. R. C., y Mesquita, M. R. (2018). Educação física escolar: os impactos sociais na vida de pessoas transexuais em Belém do Pará. Revista Interação, 2(43), 583-599, 2018. Recuperado de https://bit.ly/2T wZMTt

Brito, L. T., y Leite, M. S. (2017). Sobre masculinidades na Educação Física escolar: questões teóricas, horizontes políticos. Revista Práxis Educativa, 2(12), 481-500. Recuperado de https://bit.ly/3fbrznt.

Brito, L. T., y Santos, M. P. (2013). Masculinidades na Educação Física escolar: um estudo sobre os processos de inclusão/exclusão. Revista Brasileira de Educação Física e Esporte, 2(27), 235-246. Recuperado de https://bit.ly/ 2A3naRN.

Butler, J. (2018). Corpos em aliança e a politica das ruas. notas para uma teoria performativa de assembleia (Trad. F. S. Miguens). Rio de Janeiro: Civilização Brasileira. 
Butler, J. (2019). Corpos que importam. os limites discursivos do "sexo" (Trad. V. Daminelli y D. Y. Françoli). São Paulo: n-1 edições.

Butler, J. (2015). Problemas de gênero: feminismo e subversão da identidade (Trad. R. Aguiar),(8 ed.). Rio de Janeiro: Civilização Brasileira.

Candau, V. M. (2018). Interculturalidade e cotidiano escolar. En Candau, V. M. (Ed). Didática. tecendo/reinventando saberes e práticas. (1 ed.), (pp.220-235). Rio de Janeiro: 7 Letras.

Castro, S. (2018). O papel das escolas no combate às masculinidades tóxicas. Revista Aprender, 20(12), 75-82. Recuperado de https://bit.ly/2ZQQqG 7.

Cavaleiro, M. C., y Vianna, C. (2010). Chutar é preciso? masculinidades e Educação Física escolar. En Knijnik, J. D., Zuzzi, R. P. (Eds.). Meninas e meninos na Educação Física: gênero e corporeidade no século XXI (pp.137-154). Jundiaí: Fontoura.

Corsino, L. N., y Auad, D. (2012). O professor diante das relaçóes de gênero na Educação Física escolar. São Paulo: Cortez.

Couto Junior, D. R., Brito, L. T., Pocahy, F., y Amaro, I. (2019). Jovens em estado de alerta no Facebook: diálogos tecidos em/na rede como estratégia de (re-)existência à regulação das vidas precarizadas. Revista Práxis Educativa, 3(14), 1210-1229. Recuperado de https://bit.ly/3evCz co.

Devide, F. P., Osborne, R., Silva, E., Ferreira, R. C., Clair, E. S., y Nery, L. C. P. (2011). Estudos de gênero na Educação Física brasileira. Motriz, 1(11), 93-103. Recuperado de https://bit.ly/2ASMKt3.

Devide, F. P., Lima, F. R., Batista, R. S., y Rodrigues, F. S J. (2010). Exclusão intrassexo em turmas femininas na Educação Física escolar: quando a diferença ultrapassa a questão de gênero. En Knijnik, J. D., Zuzzi, R. P. (Ed.). Meninas emeninos na Educação Física: gênero e corporeidade no século XXI (pp. 87-105). Jundiaí: Fontoura.

Dornelles, P., y Wenetz, I. (2019). Educação Física escolar e o trato pedagógico com o esporte: proposições contrassexuais. En: Pereira, E. G. B. y Silva, A. C. (Eds.).Educação Física, esporte e queer: sexualidades em movimentos (pp. 39-60). Curitiba: Appris.

Dornelles, P. G. (2011). Marcas de gênero na Educação Física escolar: a separação de meninos e meninas em foco. Motrivivência, 1(37), 12-29. Recuperado de https://bit.ly/2TzRDhs.

Duque, T. (2020). Apesar de conquista no STF “ideologia de gênero" seguirá como agenda moral.Justificando. Carta Capital. Recuperado de https://b it.ly/3ayrnhn.

Felipe, J. (2009). Estudos culturais, gênero e infância: limites e possibilidades de uma metodologia em construção. Revista Textura, 19-20(11), 4-13. Recuperado de https://bit.ly/3c11jrB.

Franco, N. (2020). A Educação Física como território de demarcação dos gêneros possíveis: vivências escolares de pessoas travestis, transexuais e transgêneros. Motrivivência, 47(28), 47-66. Recuperado de https://bit.ly /3awmoob.

Garcia, R. M., y Brito, L. T. (2018). Performatizações queer na Educação Física escolar. Movimento, 4(24), 1321-1334. Recuperado de https://bit.ly/3qJ mqr0. 
Goellner, S. V. (2013). A contribuição dos estudos de gênero e feministas para o campo acadêmico-profissional da Educação Física. En Dornelles, P. G., Wenetz, I., y Schwengeber, M. S. V. (Eds.). Educação Física e gênero: desafios educacionais (pp.23-44). Ijuí: Unijuí.

Jardim, J. (2020). Cisheteronormatividade, MMA, Educação Física e sociedade. Movimentalidade. Recuperado de https://bit.ly/2AY7zn6.

Junqueira, R. (2012). Pedagogia do armário: heterossexismo e vigilância de gênero no cotidiano escolar. Educação on-line, 1(10), 64-83. Recuperado de https://bit.ly/36zc8A4.

Meyer, M., y Paraíso, M. A. (2014). Metodologias de pesquisas pós-críticas ou sobre como fazemos nossas investigações. En Meyer, M., y Paraíso, M. A. (Eds.). Metodologias de pesquisas pós-críticas em Educação (2 ed.), (pp.17-24). Belo Horizonte: Mazza Edições.

Miskolci. R. (2018). Exorcizando um fantasma: os interesses por trás do combate à "ideologia de gênero". Cadernos Pagu, 1(53), 01-14. Recuperado de htt ps://bit.ly/2T8a64l.

Moraes e Silva, M., y César, M. R. A. (2012). As masculinidades produzidas nas aulas de Educação Física: percepções docentes. Motrivivência, 1(39), 101-112. Recuperado de https://bit.ly/3glj5cv.

Neira, M. G. (2011). Educação Física, São Paulo: Blucher.

Neira, M. G., y Nunes, M. L. F. (2009). Educação Física, currículo e cultura. São Paulo: Phorte.

Nicolino, A. S., y Paraíso, M. A. (2018). Escolarização da sexualidade: o silêncio como prática pedagógica da Educação Física. Movimento, 1(24), 93-106. Recuperado de https://bit.ly/36vXrxI.

Pereira, E. G. B., y Brito, L. T. (2018). Meninos de verdade: discursos de masculinidades da Educação Física infantil. En Caetano, M., y Silva Junior, P. M. (Eds.). De guri a cabra-macho: masculinidades no Brasil (pp. 212-230). Rio de Janeiro: Lamparina.

Pineda, F. L. (2009) É hora de sacudir os velhos preconceitos e de construir a Terra: sobre a educação intercultural. En Candau, V. M. (Ed.). Educação Intercultural na América Latina. entre concep̧̧óes, tensões e propostas. (pp. 94-123) Rio de Janeiro: 7Letras.

Prado, V. M., y Ribeiro, A. I. M. (2016). Escola, homossexualidades e homofobia: rememorando experiências na Educação Física escolar. Revista reflexão e ação, 1(24), 97-114. Recuperado de https://bit.ly/2WYFMLN.

Preciado, P. B. (2014). Manifesto Contrassexual (Trad. M. P. G. Ribeiro). São Paulo: $\mathrm{n}-1$ edições.

Salih, S. (2012). Judith Butler e a teoria queer (Trad. G. L. Louro). Belo horizonte: Autêntica Editora.

Santos, A. P. S., y Canen, A. (2015). A prática pedagógica na perspectiva multi/ intercultural e as relações de gênero: possibilidades de ação na Educação Física escolar. Arquivos em Movimento, 1(10), 69-86. Recuperado de htt ps://bit.ly/3bYxMii.

Scott, J. (1994). Deconstruir igualdad-versus-diferencia: usos de la teoría posestructuralista para el feminismo. Revista feminaria, 13(7), 1-9. Recuperado de https://bit.ly/2tanixz. 
Sousa, E. S., y Altmann, H. (1999). Meninos e meninas: expectativas corporais e implicações na Educação Física escolar. Cadernos Cedes, 48(19), 52-68. Recuperado de https://bit.ly/2X0HRqB.

Sousa Filho, A. (2015). Editorial. "Ideologia de gênero": quem pratica? Revista Bagoas, 12(9), 9-14. Recuperado de https://bit.ly/362wrxo.

Thiollent, M. (2011). Metodologia da pesquisa-ação (18 ed). São Paulo: Cortez.

Warner, M. (1993). Fear of a queer planet: queer politics and social theory. Minnesota: Minnesota Press.

Weller, W. (2006). Grupos de discussão na pesquisa com adolescentes e jovens: aportes teórico-metodológicos e análise de uma experiência com o método. Educação e pesquisa, 2(32), 241-260. Recuperado de https://bit.ly/36tgW XA.

\section{Notas}

1 TF declara inconstitucional lei municipal que proíbe debate de gênero nas escolas. Disponível em: . Acesso em: 17 de mai. 2020.

2 Os estudos de gênero na Educação Física, em seu desenvolvimento no âmbito acadêmico, ampliaram seus enfoques para outras temáticas, tais como os estudos sobre masculinidades (Cavaleiro \& Vianna, 2010; Moraes e Silva \& César, 2012; Brito \& Leite, 2017; Pereira \& Brito, 2018), a abordagem da sexualidade e da orientação sexual (Prado \& Ribeiro, 2016; Nicolino \& Paraíso, 2018; Dornelles \& Wenetz, 2019), além da questão da transgeneridade (Franco, 2016; Barroso, Cardoso \& Mesquita, 2018).

3 Utilizamos o termo sexo, reconhecendo que sua fixidez, pautada pelas questões biológicas, justificou historicamente a separação de meninos e meninas nas aulas de Educação Física escolar. Entretanto, reconhecemos, como aponta Butler (2015), que a categoria sexo também é uma construção social.

4 Este é um recorte da dissertação de mestrado intitulada A Educação Física em uma perspectiva multi/intercultural e as relações de gênero no contexto escolar, defendida pela primeira autora deste artigo, no ano de 2013, pelo Programa de Pós-graduação em Educação da Universidade Federal do Rio de Janeiro (PPGE-UFRJ).

5 A pesquisa-ação é uma estratégia metodológica da pesquisa social que além de ter uma ampla interação entre pesquisadores/as e sujeitos pesquisados caminha no sentido de promover ações concretas para solucionar os problemas detectados no contexto em questão e aumentar o nível de consciência de todos/as os/as envolvidos/as (Thiollent, 2011). 